\title{
Bitter gourd (Momordica charantia) improves insulin sensitivity by increasing skeletal muscle insulin-stimulated IRS-1 tyrosine phosphorylation in high-fat-fed rats
}

\author{
M. G. Sridhar*, R. Vinayagamoorthi, V. Arul Suyambunathan, Z. Bobby and N. Selvaraj \\ Department of Biochemistry, Jawaharlal Institute of Postgraduate Medical Education and Research (JIPMER), \\ Pondicherry-605 006, India
}

(Received 14 March 2007 - Revised 10 August 2007 - Accepted 13 August 2007)

The aim of this present study was to investigate the effect of bitter gourd extract on insulin sensitivity and proximal insulin signalling pathways in high-fat-fed rats. High-fat feeding of male Wistar rats for 10 weeks decreased the glucose tolerance and insulin sensitivity compared to chow-fed control rats. Bitter gourd extract supplementation for 2 weeks (9th and 10th) of high-fat feeding improved the glucose tolerance and insulin sensitivity. In addition bitter gourd extract reduced the fasting insulin (43 (SE 4.4) v. 23 (SE 5.2) $\mu \mathrm{U} / \mathrm{ml}, P<0.05$ ), TAG (134 (SE 12 ) v. 96 (SE 5.5) $\mathrm{mg} / \mathrm{dl}, P<0.05$ ), cholesterol (97 (SE 6.3) v. 72 (SE 5.2) mg/dl, $P<0.05$ ) and epidydimal fat (4.8 (SE 0.29) v. 3.6 (SE 0.24$) \mathrm{g}, P<0.05$ ), which were increased by high-fat diet (HFD). High-fat feeding and bitter gourd supplementation did not have any effect on skeletal muscle insulin receptor, insulin receptor subtrate-1 (IRS-1) and insulin- stimulated insulin receptor tyrosine phosphorylation compared to chow-fed control rats. However high-fat feeding for 10 weeks reduced the insulin-stimulated IRS-1 tyrosine phosphorylation compared to control rats. Bitter gourd supplementation together with HFD for 2 weeks improved the insulin-stimulated IRS-1 tyrosine phosphorylation compared to rats fed with HFD alone. Our results show that bitter gourd extract improves insulin sensitivity, glucose tolerance and insulin signalling in HFD-induced insulin resistance. Identification of potential mechanism(s) by which bitter gourd improves insulin sensitivity and insulin signalling in high-fat-fed rats may open new therapeutic targets for the treatment of obesity/dyslipidemia-induced insulin resistance.

Bitter gourd: Obesity: Hyperinsulinaemia: Insulin sensitivity: Insulin signalling

Insulin is a powerful pan-metabolic hormone. A major physiological effect of insulin is maintenance of whole-body glucose homeostasis ${ }^{1}$. Insulin regulates glucose homeostasis mainly by increasing the transport of glucose into the skeletal muscle. Insulin binding to the $\alpha$-subunits of its receptor triggers its intrinsic tyrosine kinase activity of the $\beta$-subunits. The autophosphorylated insulin receptor phosphorylates the tyrosine residues of insulin receptor substrate-1 (IRS-1). IRS-1 tyrosine phosphorylation promotes the transcriptional and mitogenic activity of insulin through a mitogen-activated protein kinase cascade, while activation of the phosphatidyl inositol-3 kinase pathway is engaged with the hormone's metabolic effects $^{2}$. In muscle and fat cells, the glucose transport is mediated through the insulin-stimulated translocation of intracellular GLUT 4 isoforms to the cell surface via phosphatidyl inositol-3 kinase activation.

Insulin resistance is the salient feature of type 2 diabetes mellitus. Insulin resistance occurs when normal circulating concentrations of the hormone fail to regulate body glucose homeostasis ${ }^{3}$. Although many insulin-sensitizing agents are widely available, interest is evoked in dietary adjuvants that possess hypoglycaemic properties. More than 400 herbal products have been used to lower blood glucose, but only a small number of these have received scientific and medical evaluation to assess their efficiency ${ }^{4}$. Among them, Momordica charantia, commonly known as bitter gourd (BG), bitter melon and karela, belonging to the Curcurbitaceae family has been a popular herbal recourse. It is a climber plant, cultivated throughout southern Asia and its fruits are available throughout the year. BG has received widespread attention in the scientific community due to its beneficial effects, including anti-diabetic, anti-cancer and anti-inflammatory effects in laboratory studies 5 .

BG has been used to treat diabetes since the 16th century. Although various parts (roots, stems, leaves and fruits) of BG are used traditionally, studies have shown that the fruit extract of BG possesses potent hypoglycaemic properties ${ }^{6-7}$, while the seeds and other parts have little or no effects ${ }^{8}$. Hypoglycaemic effects of BG fruit extracts have been demonstrated in various animal models of insulin resistance $^{9-10}$. Recent in vitro studies in $\mathrm{C} 2 \mathrm{C} 12$ myocytes and 3T3-L1 adipocytes demonstrated the role of BG extract in improving insulin-stimulated glucose uptake ${ }^{6,11}$. Even though the insulin-sensitizing property of BG has been noted, the molecular mechanisms by which BG improves insulin sensitivity are not clear. To the best of our knowledge 
the effect of BG on insulin signalling has not been studied. In view of the above, this study was designed to explore the effect of crude BG fruit extract on insulin sensitivity and insulin signalling in high-fat diet (HFD) induced insulinresistant rats, which mimic the obesity/dyslipidemia-induced insulin resistance in human subjects.

\section{Materials and methods}

\section{Materials}

Insulin receptor $\beta$-subunit, IRS-1 and phosphotyrosine antibodies were purchased from Cell Signalling Technology, Inc. (Danvers, MA, USA). Protein-A agarose was purchased from Bangalore Genei (Bangalore, India). Human recombinant insulin and all other chemicals were purchased from Sigma Chemicals (St.Louis, MO, USA).

\section{Animals}

Male Wistar rats weighing $150-200 \mathrm{~g}$ were housed at $22 \pm 2^{\circ} \mathrm{C}$ with a $12: 12 \mathrm{~h}$ dark-light schedule. All the experimental protocols used in this study were approved by the Institute Animal Experimentation Ethics Committee. Animals were randomly assigned to three groups. The control group was maintained on normal rodent chow for 10 weeks. The experimental groups were treated with a purified HFD for 10 weeks (HFD group) or with a HFD for 10 weeks supplemented with BG extract for the last two weeks of highfat feeding (HFD + BG group). Each group consisted of eight animals. The semi-purified HFD was prepared as described previously ${ }^{12}$, with $59 \%$ of total calories derived from fat, $21 \%$ from protein and $20 \%$ from carbohydrate. The energy content of the HFD was $21.84 \mathrm{~kJ} / \mathrm{g}(5.2 \mathrm{kcal} / \mathrm{g})$, whereas that of the chow diet was $13.86 \mathrm{~kJ} / \mathrm{g}(3.3 \mathrm{kcal} / \mathrm{g})$. The rats were provided with the respective diet and water ad libitum.

\section{Preparation of bitter gourd fruit extract}

The crude BG fruit extract was prepared as described previously ${ }^{13}$. Fresh BG fruits purchased from the local market were washed thoroughly with tap water, cut open and the seeds were removed. The washed fruits were cut into small pieces and then crushed with pestle and mortar, followed by the collection of juice through muslin to remove the debris. The yield was found to be about $15 \mathrm{ml} / 100 \mathrm{~g}$ BG. The juice was administered to the animals once daily in the morning through oral gavage at a dose of $10 \mathrm{ml} / \mathrm{kg}$ per $\mathrm{d}$.

\section{Intraperitoneal glucose tolerance test}

An intraperitoneal glucose tolerance test was done at the baseline, after 8 weeks and after 10 weeks of HFD treatment as described previously ${ }^{14}$. After an overnight fast, rats were injected intraperitonealy with glucose $(2.0 \mathrm{~g} / \mathrm{kg}$ body weight $)$ and blood samples were collected at different time intervals to estimate plasma glucose. Area under the curve of each group was calculated using NCCS software.

\section{Intraperitoneal insulin tolerance test}

Intraperitoneal insulin tolerance test was done at the baseline, after 8 weeks and after 10 weeks of HFD treatment as described previously ${ }^{14}$. After $6 \mathrm{~h}$ fasting, rats were injected intraperitonealy with $2 \cdot 0 \mathrm{U}$ insulin/ $\mathrm{kg}$ and blood samples were collected at different time intervals to estimate plasma glucose. Area under the curve of each group was calculated using NCCS software.

\section{Analysis of plasma metabolic profile}

After 10 weeks, glucose, TAG and total cholesterol were estimated in overnight fasting plasma samples using standard reagent kits in 550 Express plus autoanalyser (Bayers Diagnostics, New York, USA). Overnight fasting plasma insulin was estimated using rat insulin ELISA kit (Boehringer, Mannheim, Germany).

\section{Insulin stimulation}

At the end of the 10th week animals were sacrificed with and without insulin stimulation. Insulin stimulation was performed by intraperitoneal injection of $15 \mathrm{U}$ human recombinant insu$\mathrm{lin} / \mathrm{kg}$. After a wait of $30 \mathrm{~min}$ for the maximum effect of insulin to occur ${ }^{15}$, the animals were sacrificed and the gastrocnemius muscle was removed, frozen in liquid $\mathrm{N}_{2}$ and stored at $-70^{\circ} \mathrm{C}$ for subsequent immunoblotting analysis.

\section{Preparation of muscle homogenate and Western blotting}

Muscle homogenates were prepared in homogenization buffer $(50 \mathrm{~mm}$ Tris- $\mathrm{HCl} \mathrm{pH} 7.4,1 \%$ Nonidet P-40, $0.25 \%$ sodium deoxycholate, $150 \mathrm{~mm} \mathrm{NaCl}, 1 \mathrm{~mm}$ sodium vandate, $1 \mathrm{~mm}$ phenyl methyl sulfonyl fluoride, $1 \mathrm{~mm}$ aprotinin, $1 \mathrm{~mm}$ leupeptin, $0.5 \mu \mathrm{g}$ okadaic acid $/ \mathrm{ml}$ ) as described previously ${ }^{16}$. Homogenates were centrifuged at $4^{\circ} \mathrm{C}$ at $12000 \mathrm{~g}$ for $15 \mathrm{~min}$, supernatant collected and protein content was estimated by the method of Bradford ${ }^{17}$. Muscle homogenates $(100 \mu \mathrm{g}$ protein) were resolved by $8.0 \%$ sodium dodecyl sulphate PAGE, electrotransferred onto nitrocellulose membrane, and immunoblotted for insulin receptor and IRS-1 with specific antibodies. Protein bands were visualized by an enhanced chemiluminescence method using ECL-kit (Amersham Pharmacia Biotech, New Jersey, USA). Bands were scanned using a densitometer (Biorad, Model GS-710, Hercules, California) and quantified by Quantity 1 software (Biorad).

\section{Immunoprecipitation and immunoblotting}

Muscle homogenates $(200 \mu \mathrm{g}$ protein) were incubated overnight at $4^{\circ} \mathrm{C}$ with antibodies specific to insulin receptor and IRS- 1 and the immune complexes were captured by adding $50 \mu \mathrm{l}$ protein-A agarose beads. Immune complexes were pelleted at $12000 \mathrm{~g}$ for $15 \mathrm{~min}$ at $4^{\circ} \mathrm{C}$ and washed three times with homogenization buffer. The immune complexes were suspended in Laemmli sample buffer ${ }^{18}$ and boiled for $5 \mathrm{~min}$. Protein-A agarose was removed from the denatured proteins by centrifugation at $12000 \mathrm{~g}$ for $15 \mathrm{~min}$ at $4^{\circ} \mathrm{C}$. The supernatant was resolved by $8.0 \%$ sodium dodecyl sulphate PAGE and electrotransferred onto nitrocellulose membrane. 

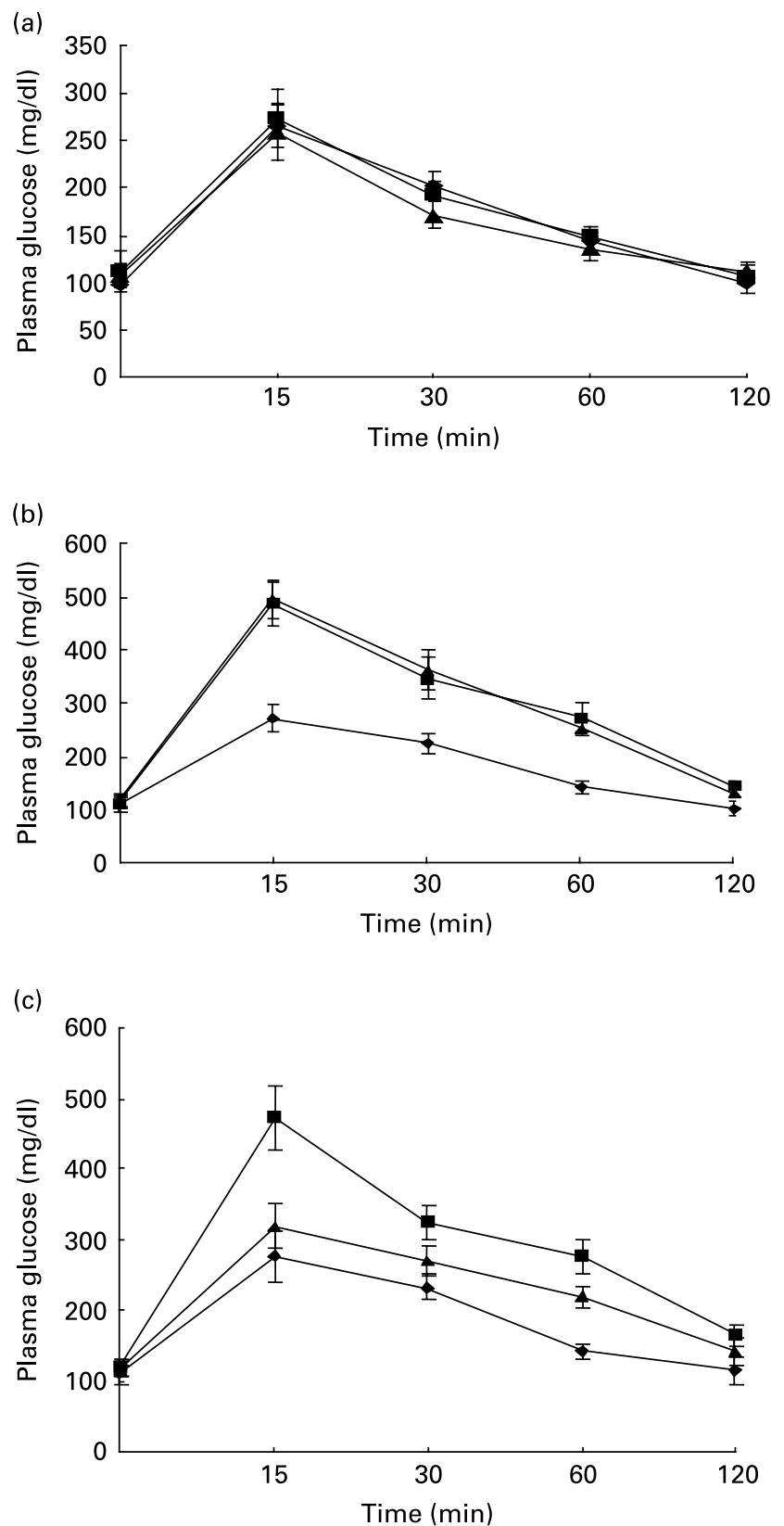

Fig. 1. Intraperitoneal glucose tolerance test on rats from experimental dietary groups $(\diamond$, control, $n 8 ; \boldsymbol{\square}$, high-fat diet (HFD), $n 8$ and $\boldsymbol{\Delta}$, HFD + bitter gourd (BG) extract, $n 8$ ) at (a) baseline, (b) 8 weeks and (c) 10 weeks. After an overnight fast, rats were injected with glucose intraperitonealy $(2.0 \mathrm{~g} / \mathrm{kg}$ body weight) and blood samples were taken at different time intervals to estimate plasma glucose. Area under the curve (AUC) of different groups was calculated using NCCS software. Data are expressed as means with their standard errors indicated by vertical bars. Statistical comparisons among the individual groups were evaluated by using one-way ANOVA followed by Tukey's post hoc test. The AUC for the control, HFD and HFD + BG groups at baseline were 10655 (SE 663), 10864 (SE 427) and 10144 (SE 714) mg/dl $\times$ min, respectively. The AUC for the control, HFD and HFD + BG groups at 8 weeks were 11297 (SE 761), 18664 (SE 1405) and 18586 (SE 1165) mg/dl $\times$ min, respectively. AUC for the HFD and HFD + BG groups at 8 weeks were significantly different from that of the control group $(P<0.05)$. The AUC for the control, HFD and HFD + BG groups at 10 weeks were 11315 (SE 746), 18106 (SE 1413) and 13922 (SE 689) mg/dl $\times$ min, respectively. AUC for the HFD and HFD + BG groups at 10 weeks were significantly different from that of the control group $(P<0.05)$. AUC for the HFD + BG group at 10 weeks was significantly different from that of the HFD group $(P<0.05)$.
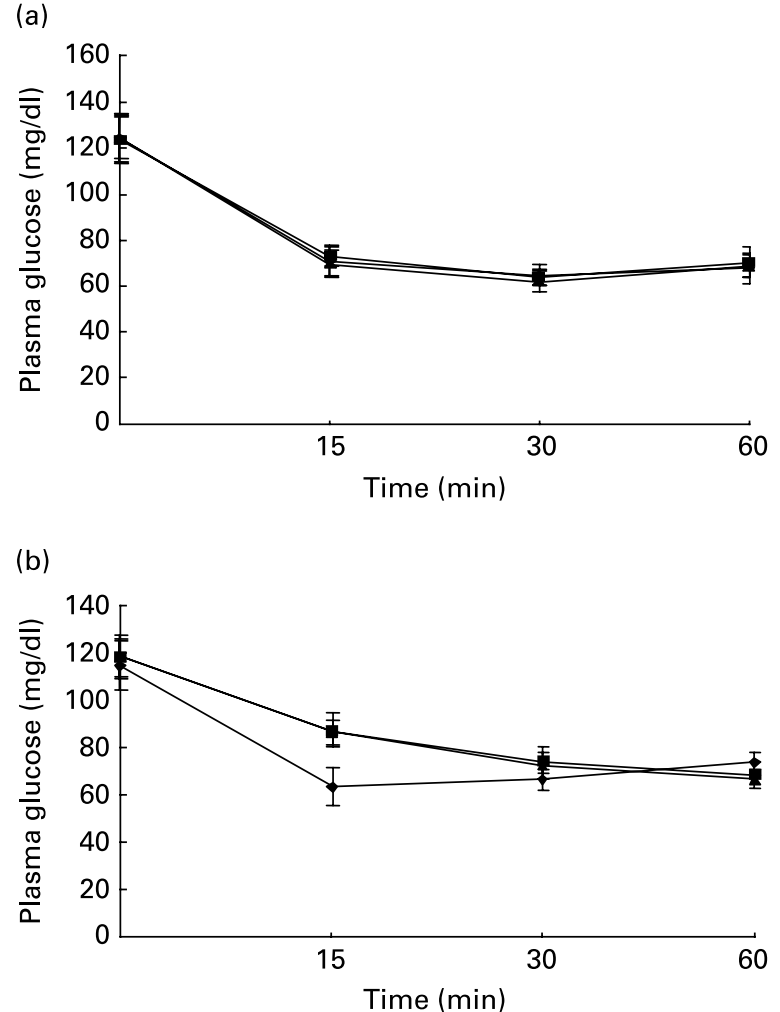

(c)

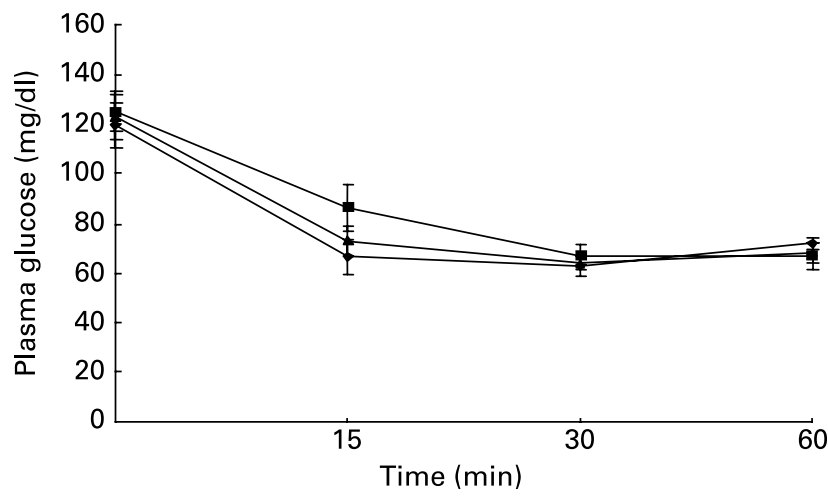

Fig. 2. Intraperitoneal insulin tolerance test on rats from experimental dietary groups ( $\bullet$, control, $n$ 8; $\mathbf{\square}$, high-fat diet (HFD), $n 8$ and $\boldsymbol{\Delta}$, HFD + bitter gourd (BG) extract, $n$ 8) at (a) baseline, (b) 8 weeks and (c) 10 weeks. After $6 \mathrm{~h}$ fast, rats were injected with insulin intraperitonealy $(2.0 \mathrm{~g} / \mathrm{kg}$ body weight) and blood samples were taken at different time intervals to estimate plasma glucose. Area under the curve (AUC) of different groups was calculated using NCCS software. Data are expressed as means with their standard errors indicated by vertical bars. Statistical comparisons among the individual groups were evaluated by using one-way ANOVA followed by Tukey's post hoc test. The AUC for the control, HFD and HFD + BG groups at baseline were 4232 (SE 106), 4458 (SE 76) and 4286 (SE 95) $\mathrm{mg} / \mathrm{dl} \times$ min, respectively. The AUC for the control, HFD and HFD + BG groups at 8 weeks were 4315 (SE 76), 5297 (SE 107) and 5342 (SE 121) mg/dl $\times$ min, respectively. AUC for the HFD and HFD + BG groups at 8 weeks were significantly different from that of the control group $(P<0.05)$. The AUC for the control, HFD and HFD + BG groups at 10 weeks were 4329 (SE 92), 5676 (SE 113) and 4973 (SE 79) $\mathrm{mg} / \mathrm{dl} \times \mathrm{min}$, respectively. AUC for the HFD and HFD + BG groups at 10 weeks were significantly different from that of the control group $(P<0.05)$. AUC for the HFD + BG group at 10 weeks was significantly different from that of the HFD group $(P<0.05)$. 
Proteins were probed with antibodies specific to phosphotyrosine residues and immunoblot was stripped of bound antibodies and then reprobed with antibody specific to insulin receptor and IRS-1 to normalize the tyrosine phosphorylation with corresponding proteins. Protein band detection and quantification were performed as mentioned earlier.

\section{Statistical analysis}

Results were expressed as means with their standard errors. Statistical comparison of means among individual groups was done using one-way ANOVA followed by Tukey post hoc test. A value of $P<0.05$ was considered significant.

\section{Results}

Effect of bitter gourd on glucose tolerance and insulin sensitivity

Figs. 1 and 2 show the effect of HFD and BG treatment on glucose tolerance and insulin sensitivity in male Wistar rats. High-fat feeding shows impaired glucose tolerance and decreased insulin sensitivity. BG treatment for 2 weeks significantly improved the glucose tolerance and insulin sensitivity in rats fed with HFD.

\section{Effect of bitter gourd on plasma metabolic profile and} adiposity

High-fat feeding for 10 weeks significantly increased the plasma TAG, total cholesterol, insulin, body weight and epidydimal fat weight in male Wistar rats (Table 1). BG supplementation for 2 weeks to the high-fat-fed rats significantly reduced the plasma TAG, total cholesterol, insulin and epidydimal fat weight, but there was no significant effect on plasma fasting glucose and body weight.

\section{Effect of bitter gourd on insulin signalling}

High-fat feeding and BG supplementation did not have any significant effect on the amount of insulin receptor (Fig. 3(a)), IRS-1 (Fig. 3(c)) and insulin-stimulated tyrosine phosphorylation of insulin receptor compared to control rats
(Fig. 3(b)). High-fat feeding significantly reduced the insulinstimulated IRS-1 tyrosine phosphorylation compared to control rats. BG supplementation for 2 weeks together with HFD showed a significant increase in insulin- stimulated tyrosine phosphorylation of IRS-1 compared to rats fed with HFD alone (Fig. 3(d)).

\section{Discussion}

In the present study, we have investigated the effect of BG fruit extract on high-fat-fed rats. High-fat feeding to male Wistar rats caused insulin resistance, increased the plasma TAG, cholesterol, body weight and adiposity. BG extract treatment for 2 weeks $(10 \mathrm{ml} / \mathrm{kg}$ per d) along with HFD improved insulin sensitivity, decreased the plasma lipids and adiposity. BG supplementation also improved the skeletal muscle proximal insulin signalling which was impaired by HFD.

Numerous studies have shown the development of insulin resistance as a result of increased intake of dietary fat 12,15,19. An impaired ability of insulin to stimulate glucose uptake in skeletal muscle with high-fat feeding both in vivo and in vitro has been documented ${ }^{20,21}$. Previous studies in high-fat-fed rats demonstrated decreased insulin-stimulated phosphatidyl inositol-3 kinase activity and GLUT4 translocation $^{22}$. These reports suggest a defect in the proximal insulin signalling pathway as a result of fat intake. In the present study, high-fat feeding and BG supplementation did not affect skeletal muscle insulin receptor content or its insulinstimulated tyrosine phosphorylation. However, our results show no effect of HFD on IRS-1 content, but HFD decreases insulin-stimulated IRS-1 tyrosine phosphorylation. BG supplementation to high-fat-fed rats improves the insulin-stimulated IRS-1 tyrosine phosphorylation and insulin sensitivity. Studies have shown the importance of IRS-1 in insulin signalling $^{23,24}$. IRS-1 knock out mice show impaired insulin signalling and severe insulin resistance ${ }^{25}$. Recent studies demonstrate decreased insulin-stimulated IRS-1 tyrosine phosphorylation as a potential molecular mechanism for insulin resistance ${ }^{26,27}$

Over the years, several mechanisms have been put forward to explain the hypoglycaemic effect of BG. Similarly to glucosidase inhibitors, a fraction that competitively inhibits

Table 1. Plasma metabolic profile of experimental dietary groups after 10 weeks. Body weight and epidydimal fat weight were measured in male Wistar rats. Plasma parameters were measured in overnight-fasted rats. Statistical comparison among the individual groups was evaluated by using one-way ANOVA followed by Tukey's post hoc test

(Mean values with their standard errors)

\begin{tabular}{|c|c|c|c|c|c|c|}
\hline \multirow[b]{2}{*}{ Parameters } & \multicolumn{2}{|c|}{ Control (n 8) } & \multicolumn{2}{|c|}{ HFD $(n 8)$} & \multicolumn{2}{|c|}{$\mathrm{HFD}+\mathrm{BG}(n 8)$} \\
\hline & Mean & SE & Mean & SE & Mean & SE \\
\hline Body weight (g) & 181 & 10 & $224^{*}$ & 9 & $214^{*}$ & 16 \\
\hline Epidydimal fat (g) & 2.9 & 0.22 & $4 \cdot 8^{*}$ & 0.29 & $3 \cdot 6^{\star} \dagger$ & 0.24 \\
\hline Plasma glucose (mg/dl) & 96 & 13 & 103 & 9 & 106 & 11 \\
\hline Plasma insulin $(\mu \mathrm{U} / \mathrm{ml})$ & 21 & 2.5 & $43^{*}$ & 4.4 & $23+$ & $5 \cdot 2$ \\
\hline Plasma TAG $(\mathrm{mg} / \mathrm{dl})$ & 80 & $7 \cdot 2$ & $134^{*}$ & 12 & $96^{*} \dagger$ & 5.5 \\
\hline Plasma total cholesterol (mg/dl) & 63 & $4 \cdot 2$ & $97^{*}$ & $6 \cdot 3$ & $72^{*} \dagger$ & $5 \cdot 2$ \\
\hline
\end{tabular}

HFD, high-fat diet; BG, bitter gourd.

Mean values were significantly different from those for the control group: ${ }^{*} P<0.05$

Mean values were significantly different from those for the HFD group: $\dagger P<0.05$. 
(a)

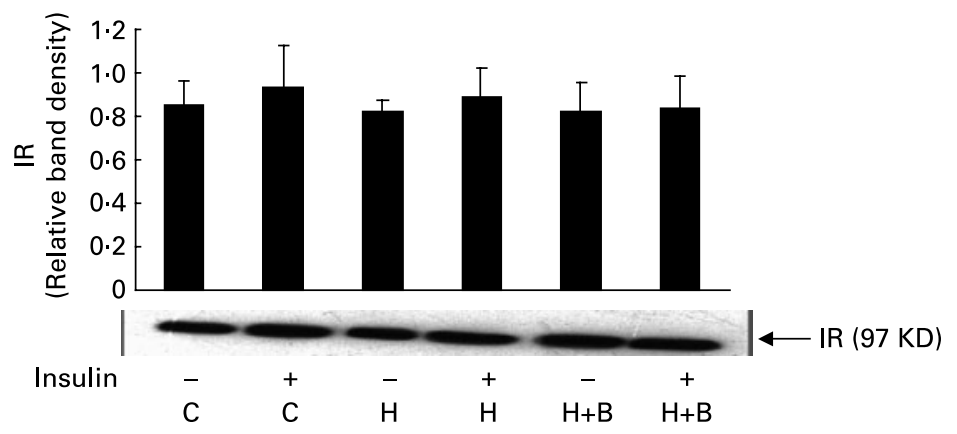

(b)

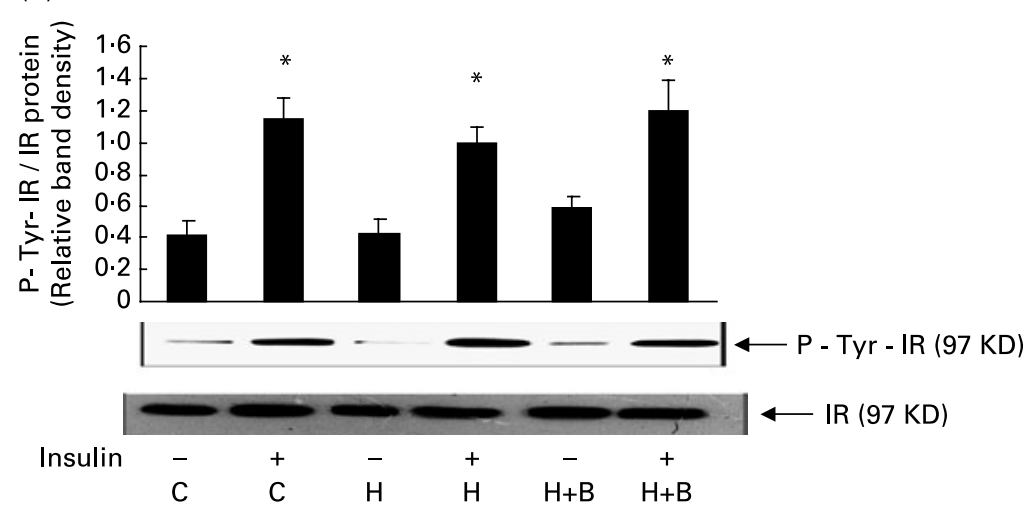

(c)

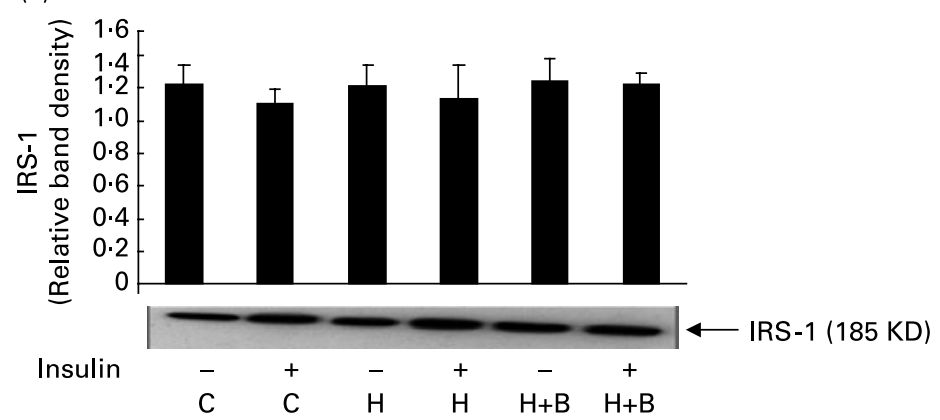

(d)

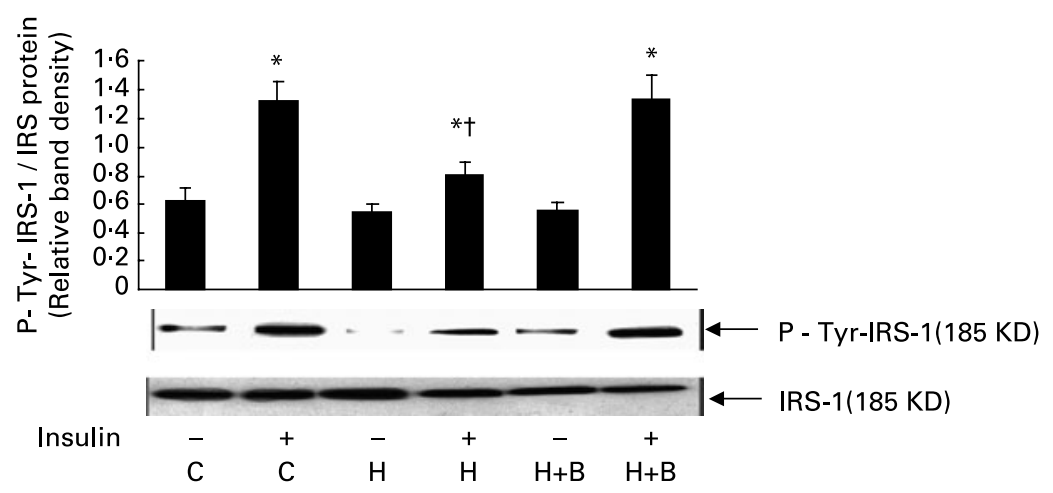

Fig. 3. Effect of bitter gourd on insulin signalling. (a), (c), Muscle homogenate (100 $\mu$ g protein) was resolved by $8 \%$ sodium dodecyl sulphate PAGE, electrotransferred onto nitrocellulose membrane, and immunoblotted with antibody specific to insulin receptor (IR) or insulin receptor subtrate-1 (IRS-1). (b), (d), Muscle homogenate $\left(200 \mu \mathrm{g}\right.$ protein) was incubated overnight at $4^{\circ} \mathrm{C}$ with antibody specific to IR or IRS-1 and the immune complex was captured by adding $50 \mu$ l protein-A agarose beads, suspended in Laemmli sample buffer, resolved by $8.0 \%$ sodium dodecyl sulphate PAGE and transferred to nitrocellulose membrane. Proteins were immunoblotted with antibody specific to phosphotyrosine (P-Tyr) and immunoblot was stripped of bound antibodies and then reprobed with antibody specific to IR or IRS-1. A representative immunoblot of three independent experiments is shown. Results shown are means with standard errors of three experiments. C, Control; $\mathrm{H}$, high-fat diet (HFD); H + B, HFD + bitter gourd; -, baseline and +, insulin stimulation. Mean values were significantly different compared to baseline: ${ }^{*} P<0.001$. Mean values were significantly different compared to insulin-stimulated control: $\dagger P<0.001$ 
intestinal glucose absorption has been reported ${ }^{28}$. An $11 \mathrm{kDa}$ protein isolated from BG shows hypoglycaemic activity ${ }^{6}$. Studies have shown BG induced insulin release from isolated pancreatic islet cells ${ }^{29}$. In the present study the insulin sensitizing action of $\mathrm{BG}$, whether it is via regulation of insulin release or altered glucose metabolism or by its insulin-like effect is not clear. Recent studies have shown activation of PPAR by BG extract ${ }^{30,31}$. PPAR are ligand-dependent transcription factors that belong to the steroid hormone nuclear receptor family and control lipid and glucose metabolism in the body ${ }^{32}$. PPAR $y$ is mainly expressed in adipocytes and mediates their differentiation ${ }^{33}$. The thiazolidinediones are PPAR $\gamma$ agonists, improve insulin signalling and insulin sensitivity $^{34}$. PPAR $\alpha$ is widely expressed in liver, muscle and kidney $^{35}$ and regulates expression of genes promoting fatty acid oxidation ${ }^{36,37}$. The fibrate class PPAR $\alpha$ agonists are effective drugs in clinical use to reduce circulating lipids ${ }^{31,35-37}$. In the present study the insulin sensitizing and hypolipidaemic property of BG might be due to the activation of PPAR $\gamma$ and PPAR $\alpha$. Recent reports show high-fat induced activation of serine kinases, which can down regulate IRS-1 tyrosine phosphorylation through increased IRS-1 serine phosphorylation $^{38,39}$. Increased IRS-1 serine phosphorylation impairs its interaction with the juxtamembrane domain of insulin receptor and may thus render it a poorer substrate for insulin receptor tyrosine kinase ${ }^{40}$. Several studies show that agents which inhibit serine kinases, improve IRS-1 tyrosine phosphorylation and insulin sensitivity ${ }^{41,42}$. Another possible explanation, by which BG improves IRS-1 tyrosine phosphorylation may be by preventing or inhibiting the activation of serine kinases. Further studies are clearly warranted to firmly establish these links.

\section{Conclusion}

We found high-fat feeding to rats causes insulin resistance and impaired insulin signalling. Treatment with BG for two weeks significantly improved insulin signalling and insulin sensitivity in high-fat-fed rats. Identification of potential molecule(s) present in BG and its molecular basis of improving insulin signalling in insulin resistance might lead to the discovery of novel therapeutic targets and agents to prevent, reverse or delay the onset of insulin resistance.

\section{References}

1. Saltiel AR \& Pessin JE (2002) Insulin signalling pathways in time and space. Trends in Cell Biol 12, 65-71.

2. Pessin JE \& Saltiel AR (2000) Signalling pathways in insulin action: molecular targets of insulin resistance. J Clin Invest 106, 165-169.

3. Shulman GI (2000) Cellular mechanisms of insulin resistance. J Clin Invest 106, 171-176.

4. Sathishseker D \& Subramanian S (2005) Antioxidant properties of Momordica charantia (bitter gourd) seeds on streptozotocin induced diabetic rats. Asia Pac J Clin Nutr 14(2), 153-158.

5. Grover JK \& Yadav SP (2004) Pharmacological actions and potential uses of Momordica charantia: a review. J Ethnopharmacol 93, 123-132.

6. Yibchok-Anun S, Adisakwattana S, Yao CY, Sangvanich P, Roengsumran S \& Hsu WH (2006) Slow acting protein extract from fruit pulp of Momordica charantia with insulin secretagogue and insulinomimetic activities. Biol Pharm Bull 29(6), $1126-1131$.

7. Miura T, Itoh $Y$, Iwamoto N, Kato $M$ \& Ishida T (2004) Suppressive activity of the fruit of Momordica charantia with exercise on blood glucose in type 2 diabetic mice. Biol Pharm Bull 27(2), 248-250.

8. Ali L, Khan AK, Mamun MI, Mosihuzzaman M, Nahar N, Nure-Alam M \& Rokeya B (1993) Studies on hypoglycemic effects of fruit pulp, seed, and whole plant of Momordica charantia on normal and diabetic model rats. Planta Med 59(5), 408-412.

9. Ahmed I, Lakhani MS, Gillett M, John A \& Raza H (2001) Hypotriglyceridemic and hypocholesterolemic effects of antidiabetic Momordica charantia (karela) fruit extract in streptozotocin-induced diabetic rats. Diabetes Res Clin Pract 51(3), $155-161$.

10. Miura T, Itoh C, Iwamoto N, Kato M, Kawai M, Park SR \& Suzuki I (2001) Hypoglycemic activity of the fruit of the Momordica charantia in type 2 diabetic mice. J Nutr Sci Vitaminol (Tokyo) 47(5), 340-344.

11. Roffey BW, Atwal AS, Johns T \& Kubow S (2007) Water extracts from Momordica charantia increase glucose uptake and adiponectin secretion in 3T3-L1 adipose cells. $J$ Ethnopharmacol 30, 77-84.

12. Storlien LH, James DE, Burleigh KM, Chisholm DJ \& Kraegen EW (1986) Fat feeding causes widespread in vivo insulin resistance, decreased energy expenditure, and obesity in rats. Am J physiol 251, E576-E583.

13. Leatherdale BA, Panesar RK, Singh G, Atkins TW, Bailey CJ \& Bignell AHC (1981) Improvement in glucose tolerance due to Momordica charantia (karela). Brit Med J 282, 1823-1824.

14. Minsheng Y, Nicky K, Jongsoon L, Lone H, Zhi-Wei Li, Micheal K \& Shoelson SE (2001) Reversal of obesity- and diet-induced insulin resistance with salicylates or targeted disruption of IKK $\beta$. Science 293, 1673-1677.

15. Youngren JF, John P \& Barnard RJ (2001) Impaired insulinreceptor autophosphorylation is an early defect in fat-fed, insulin resistant rats. Am J Physiol 91, 2240-2247.

16. Saad MJA, Araki E, Miralpeix M, Rothenberg PL, White MF \& Kohn CR (1992) Regulation of insulin receptor substrate-1 in liver and muscle of animal models of insulin resistance. $J$ Clin Invest 90, 1839-1849.

17. Bradford M (1976) A rapid and sensitive method for the quantification of microgram quantity of protein utilizing the principle of protein dye binding. Anal Biochem 72, 248-254.

18. Laemmli UK (1970) Cleavage of structural proteins during the assembly of head of bacteriophage T4. Nature 227, 680-685.

19. Hansen PA, Han DH, Marshall BA, Nolte LA, Chen MM, Mueckler M \& Holloszy JO (1998) A high fat diet impairs insulin stimulation of glucose transport in muscle. J Biol chem 273, 26157-26163.

20. Barnard RJ, Berger JJ, Ong JM \& Kern PA (1998) Adipocyte and muscle changes in response to diet leading to obesity. Diabetes 33, 213-228.

21. Barnard RJ, Roberts CK, Varon SM \& Berger JJ (1998) Diet induced insulin resistance precedes other aspects of metabolic syndrome. J Appl physiol 84, 1311-1315.

22. Oakes ND, Cooney GJ, Camilleri S, Chisholm DJ \& Kraegen EW (1997) Mechanisms of liver and muscle insulin resistance induced by chronic high-fat feeding. Diabetes 46, 1768-1774.

23. White MF (1998) The IRS-signaling system: a network of docking protein that mediate insulin and cytokine action. Recent Prog Horm Res 53, 119-138.

24. Tamemoto H, Kadowaki T, Tobe K, et al. (1994) Insulin resistance and growth retardation in mice lacking insulin receptor substrate-1. Nature 372, 182-186. 
25. Yamauchi T, Tobe K, Tamemoto H, et al. (1996) Insulin signalling and insulin actions in the muscles and livers of insulin resistant, insulin receptor substrate 1- deficient mice. Mol Cell Biol 16, 3074-3084.

26. Tanti JF, Gremeaux T, Van Obberghen E, et al. (1994) Serine/ threonine phosphorylation of insulin receptor substrate 1 modulates insulin signalling. J Biol Chem 269, 6051-6057.

27. De Fea K \& Roth RA (1997) Modulation of insulin receptor substrate -1 tyrosine phosphorylation and function by mitogen activated protein kinase. J Biol Chem 272, 31400-31406.

28. Grover JK \& Yadav SP (2004) Pharmacological actions and uses of Momordica charantia: a review. J Ethanopharmacol 93(1), 123-132.

29. Xiang L, Huang X, Chen L, Rao P \& Ke L (2007) The reparative effects of Momordica Charantia Linn. extract on HIT-T15 pancreatic beta-cells. Asia Pac J Clin Nutr 16(1), 249-252.

30. Chuang CY, Hsu C, Chao CY, Wein YS, Kuo YH \& Huang CJ (2006) Fractionation and identification of 9c, 11t, 13t-conjugated linolenic acid as an activator of PPAR alpha in bitter gourd (Momordica charantia L.). J Biomed Sci 13(6), 763-772.

31. Chao CY \& Huang CJ (2003) Bitter gourd (Momordica charantia) extract activates peroxisome proliferator-activated receptors and upregulates the expression of the acyl CoA oxidase gene in H4IIEC3 hepatoma cells. J Biomed Sci 10(2), 782-791.

32. Beatrice D \& Walter W (1999) Peroxisome proliferator - activated receptors: nuclear control of metabolism. Endocrine Reviews 20(5), 649-688.

33. Kersten S, Desvergne B \& Wahli W (2000) Roles of PPARs in health and disease. Diabetes 405, 421-424.

34. Spiegelmen BM (1997) PPAR- $\gamma$ : adipogenic regulator and thiazolidinedione receptor. Diabetes 47, 507-514.
35. Ji Ming Ye, Patric JD, Miguel A, et al. (2001) Peroxisome proliferator-activated receptor (PPAR) $-\alpha$ activation lowers muscle lipids and improves insulin sensitivity in high fat-fed rats. Comparison with PPAR- $\gamma$ activation. Diabetes 50, 411-417.

36. Forman BM, Chen J \& Evans RM (1997) Hypolipidemic drugs, polyunsaturated fatty acids, and eicosanoids are ligands for peroxisome proliferator-activated receptors $\alpha$ and $\delta$. Proc Natl Acad Sci USA 94, 4312-4317.

37. Guerre-Millo M, Gervois P, Raspe E, et al. (2000) Peroxisome proliferator-activated receptor $\alpha$ activators improve insulin sensitivity and reduce adiposity. J Biol Chem 275, 16638-16642.

38. Werner DE, Lee J, Hansen L, Yuan M \& Shoelson SE (2004) Insulin resistance due to phosphorylation of insulin receptor substrate-1 at serine 302. J Biol Chem 279, 35298-35305.

39. Kim JK, Kim YJ, Fillmore JJ, et al. (2001) Prevention of fat induced insulin resistance by salicylate. $J$ clin Invest $\mathbf{1 0 8}$, 437-448.

40. Paz K, Hemi R, LeRoith D, Karasik A, Elhanany E, Kanety H \& Zick Y (1997) A molecular basis for insulin resistance: elevated serine/threonine phosphorylation of IRS-1 and IRS-2 inhibits their binding to the juxtamembrane region of the insulin receptor and impairs their ability to under go insulin stimulated tyrosine phosphorylation. $J$ Biol Chem 272, 29911-29918.

41. Yuan M, Konstantopoulos N, Lee J, Hansen L, Li ZW, Karin M \& Shoelson SE (2001) Reversal of obesity and diet induced insulin resistance with salicylates or targeted disruption of IKK $\beta$. Science 293, 1673-1677.

42. Sykiotis GP \& Papavassiliou AG (2001) Serine phosphorylation of insulin receptor substrate-1: a novel target for the reversal of insulin resistance. Molecular Endocrinology 15, 1864-1869. 